\title{
Corrigendum: ICOS+ Tregs: A Functional Subset of Tregs in Immune Diseases
}

\author{
Dan-Yang Li and Xian-Zhi Xiong * \\ Department of Respiratory and Critical Care Medicine, NHC Key Laboratory of Pulmonary Diseases, Union Hospital, Tongji \\ Medical College, Huazhong University of Science and Technology, Wuhan, China
}

\section{OPEN ACCESS}

Approved by:

Frontiers Editorial Office,

Frontiers Media SA, Switzerland

${ }^{*}$ Correspondence: Xian-Zhi Xiong xxz0508@hust.edu.cn

Specialty section: This article was submitted to Immunological Tolerance and Regulation,

a section of the journal Frontiers in Immunology

Received: 28 April 2021 Accepted: 29 April 2021

Published: 12 May 2021

Citation:

Li D-Y and Xiong X-Z (2021) Corrigendum: ICOS+ Tregs: $A$ Functional Subset of Tregs in Immune Diseases.

Front. Immunol. 12:701515. doi: 10.3389/fimmu.2021.701515
Keywords: ICOS, Treg cells, autoimmune disease, neoplasm, immunotherapy

\section{A Corrigendum on}

ICOS+ Tregs: A Functional Subset of Tregs in Immune Diseases

By Li D-Y and Xiong X-Z (2020). Front. Immunol. 11:2104. doi: 10.3389/fimmu.2020.02104

In the published article, there was an error in the affiliations. Instead of "1 Key Laboratory of Respiratory Diseases, National Ministry of Health of the People's Republic of China, National Clinical Research Center for Respiratory Disease, Wuhan, China, ${ }^{2}$ Department of Respiratory and Critical Care Medicine, Union Hospital, Tongji Medical College, Huazhong University of Science and Technology, Wuhan, China", it should be "Department of Respiratory and Critical Care Medicine, NHC Key Laboratory of Pulmonary Diseases, Union Hospital, Tongji Medical College, Huazhong University of Science and Technology, Wuhan, China".

The authors apologize for this error and state that this does not change the scientific conclusions of the article in any way. The original article has been updated.

Copyright $(02021$ Li and Xiong. This is an open-access article distributed under the terms of the Creative Commons Attribution License (CC BY). The use, distribution or reproduction in other forums is permitted, provided the original author(s) and the copyright owner(s) are credited and that the original publication in this journal is cited, in accordance with accepted academic practice. No use, distribution or reproduction is permitted which does not comply with these terms. 